\title{
Improving communication between the general practitioner and the oncologist: a key role in coordinating care for patients suffering from cancer
}

Vladimir Druel ${ }^{1,2,3^{*}}$ (D), Laetitia Gimenez ${ }^{1,3,4}$, Kim Paricaud ${ }^{5}$, Jean-Pierre Delord ${ }^{3,6}$, Pascale Grosclaude ${ }^{4,7}$, Nathalie Boussier ${ }^{1}$ and Marie-Eve Rougé Bugat ${ }^{1,3,4,6}$ [D

\begin{abstract}
Background: Patients suffering from cancers are increasingly numerous in general practice consultations. The General Practitioner (GP) should be at the heart of the management of patients. Several studies have examined the perceptions of GPs confronted with the patient suffering from cancer and the relationships of GPs with oncologists, but few studies have focused on the patients' perspective. We studied the three-way relationship between the oncologist, the GP, and the patient, from the patient's point of view.

Methods: A questionnaire validated by a group consisting of GPs, oncologists, nurses, an epidemiologist and quality analyst, was administered over a three-week period to patients suffering from cancer receiving chemotherapy in a day hospital.

Results: The analysis was based on 403 questionnaires. Patients had confidence in the GP's knowledge of oncology in $88 \%$ of cases; $49 \%$ consulted their GP for pain, $15 \%$ for cancer-related advice, and $44 \%$ in emergencies. Perceived good GP/oncologist communication led patients to turn increasingly to their GP for cancer-related consultations (RR $=1.14$; $p=0.01)$ and gave patients confidence in the GP's ability to manage cancer-related problems (RR $=1.30 ; p<0.01)$. Mention by the oncologist of the GP's role increased the consultations for complications (RR $=1.82 ; p<0.01$ ) as well as recourse to the $\mathrm{GP}$ in an emergency ( $\mathrm{RR}=1.35 ; p<0.01)$.

Conclusion: Patients suffering from cancer considered that the GP was competent, but did not often consult their GP for cancer-related problems. There is a discrepancy between patients' beliefs and their behaviour. When the oncologist spoke to patients of the GP's role, patients had recourse to their GP more often. Systematically integrating a GP consultation to conclude cancer diagnosis disclosure, could improve management and care coordination.
\end{abstract}

Keywords: Cancer, Communication, Disclosure, General practitioner, Oncologist

\footnotetext{
* Correspondence: vladimir.druel@dumg-toulouse.fr

${ }^{1}$ Department of Primary Care, University of Toulouse, 133 Route de

Narbonne, 31062 Toulouse, France

${ }^{2}$ Oncology Unit, Auch Hospital, Auch, France

Full list of author information is available at the end of the article
}

(c) The Author(s). 2020 Open Access This article is licensed under a Creative Commons Attribution 4.0 International License, which permits use, sharing, adaptation, distribution and reproduction in any medium or format, as long as you give appropriate credit to the original author(s) and the source, provide a link to the Creative Commons licence, and indicate if changes were made. The images or other third party material in this article are included in the article's Creative Commons licence, unless indicated otherwise in a credit line to the material. If material is not included in the article's Creative Commons licence and your intended use is not permitted by statutory regulation or exceeds the permitted use, you will need to obtain permission directly from the copyright holder. To view a copy of this licence, visit http://creativecommons.org/licenses/by/4.0/ The Creative Commons Public Domain Dedication waiver (http://creativecommons.org/publicdomain/zero/1.0/) applies to the data made available in this article, unless otherwise stated in a credit line to the data. 


\section{Background}

The number of cancer diagnoses increased by 1.6 million worldwide between 2008 and 2012 [1] and by 0.7 million in Europe between 2006 and 2012 [2]. While the annual increase of cancer incidence in France is about 1\% [3], mortality decreased between 1985 and 2012 [4]. More and more patients consulting their general practitioner (GP) have, or have had, cancer [5]. The GP has a central role in the care of patients with cancer [6]. The GP intervenes at all stages of care (prevention, screening, diagnosis, treatment, follow-up, education) [7-9]. For greater equity in the management of patients suffering from cancer, a French National Cancer Plan has been implemented [10] to standardize its management. The plan proposes that the GP should be at the center of the care of patients suffering from cancer.

Collaborative care is the process through which different professional groups work together to improve healthcare quality [11]. Providers working as a team promote improved communication, coordination of care, and patient-centred shared decision making [12, 13]. A clear definition of the roles of every participant [14] and a good relationship between the patient and their GP, together with good communication between the GP and the oncologist, make for optimal care [15].

There is a general lack of trust on both sides between oncologist and GP, and communication is poor [16]. GPs often feel alienated from the hospital system [15, 17] and demand that their role in the management of patients with cancer is reinforced. For their part, $67 \%$ of patients would like to see follow-up shared between the GP and the oncologist, that is, they would like the GP to deal with both cancer-related problems (in collaboration with the specialist) and also with unrelated problems in a holistic and patient-centred approach [18, 19]. The perspective of oncologists and GPs on this question of communication have previously been examined in the literature. There is a lack of communication $[12,13,20]$ that requires the implementation of inter-professional collaboration and communication tools [20] to promote direct communication (telephone) with a patient-centred approach [12]. But few studies have focused on the patients' perspective. Those interested in it show the importance of the role of the GP and a desire on the part of patients to see an increase in the role of the GP in oncology management [21-24]. The GP participates predominantly in supportive care. It is suggested that improved communication between oncologist and GP as perceived by the patient improves the involvement of the GP [24]. In this context, we are particularly interested in the management of a patient by an oncologist and GP from the point of view of the patient. We explored this three-way relationship with the perspective of improving the coordination of cancer care.

\section{Methods}

In this purpose, a cross-sectional survey questionnaire was conducted in a sample of patients between the 15th of July and the 1st of August 2015. Patients coming for chemotherapy were invited to participate in the study and, if they consented, to complete a paper questionnaire in the day hospital of the Comprehensive Cancer Center of Toulouse (south-west France). The patients included in the study were patients with cancer over 18 years old, receiving chemotherapy in the active phase of treatment, including a patient with maintenance treatment. Patients with haematological disease or those who were not followed up by a GP were excluded. There was no other social or medical criterion of exclusion. Patients who did not accept to complete the questionnaire were not included. Questionnaires were distributed when the patients arrived for treatment and collected upon their departure. The same patient could answer the questionnaire only once. In order to limit desirability bias, the questionnaires were distributed and collected by the para-medical team (and not the medical team). These data were manually transcribed onto a spreadsheet before analysis.

This study was approved by the ethical committee of the university department of Toulouse (22nd of June 2015).

\section{Questionnaire}

The questionnaire was developed and validated after two working meetings by three GPs, two oncologists, four nurses, two nursing assistants, an epidemiologist and a quality analyst at the cancer center. It was tested by three patient volunteers, which allowed some adjustments to be made. These adjustments concerned only the wording of the questions, in order to improve their understanding. No further changes were necessary. The questionnaire included four parts: (1) the patients' characteristics, (2) their relationships with their GP, (3) GPs and cancer (history of the disease and GP involvement), and (4) relationships between GPs and oncologists from the patients' perspective. The questionnaire was written in French, and consisted of 24 closed-ended questions and one open-ended question. The questionnaire used is available in a supplementary file (see Additional files 1 \& 2).

\section{Statistical analyses}

All the characteristics of the population at inclusion, as well as the variables of interest, are described in terms of numbers and percentages (and average for each age group). Following this descriptive analysis, a comparative analysis was carried out to investigate the factors that could be associated with the change of GP. Furthermore, we analysed the associations between the patient's opinion of the relationship between GP and oncologist, and 
reasons to consult the GP, in parts (3) and (4) of the questionnaire. In this section, we focused on the patient's perception of the interaction between GP and oncologist (in the cases when the oncologist mentioned the GP's role, the GP and the oncologist communicated, and the GP's opinion was taken into account). We analyzed whether the patient's feelings influenced his or her own behaviour towards the management of oncology health problems, including complications of the oncological treatment, pain, oncological management, emergencies, as well as the competence of the GP in these situations. In order to compare the qualitative variables, a chisquared test was performed. Each bivariate analysis considered only those patients who responded to the different items analysed and the reference variable is the first mentioned in the sentence. We calculated the Risk Ratio (RR) to improve the understanding of the analyses. Statistical tests were two-sided at the 5\% level of significance. All analyses were done using STATA software version 8 .

\section{Results}

A total of 483 questionnaires were distributed, 41 patients declined to answer and 33 did not return the questionnaire, so 409 questionnaires were collected, and 403 analysed. Six were excluded: 5 because only the first page had been completed, and one because the respondent was his own GP. The response rate per question was 90 to $100 \%$ (Fig. 1).

Most patients were women (85.1\%), with a median age of 60 (mean 59.8) (Table 1). One hundred ninety-seven patients had the same GP for at least 15 years and $60.7 \%$ $(n=244)$ had visited their GP in the month before the survey. Only $4.5 \%(n=18)$ had not visited their GP for more than 6 months. About one in 5 patients had changed their GP since the cancer diagnosis. This change was not associated with the GP's participation in diagnosis significantly even if there was a trend $(\mathrm{RR}=0,67, p=$ 0,06) (Table 2).

\section{General practitioner/patient relationship}

Half the patients stated that the GP had participated in the initial diagnosis $(n=211,52.8 \%)$. Participation in diagnosis was not significantly associated with change in the frequency of GP visits $(\mathrm{RR}=0.82, p=0.74)$. Nine out of 10 patients considered that the GP was knowledgeable about the patient's specific type of cancer (i.e., knew how to support their treatment and survivorship care). The reason for the most recent GP consultation was cancer-related in $71.7 \%$ of cases $(n=289)$. Multiple reasons for consultation were possible (Fig. 1).

According to the patients' answers, $42.4 \%$ of the oncologists had mentioned the GP's role; when the oncologist had involved the GP by mentioning the GP's role in management, this had an impact on the proportion of

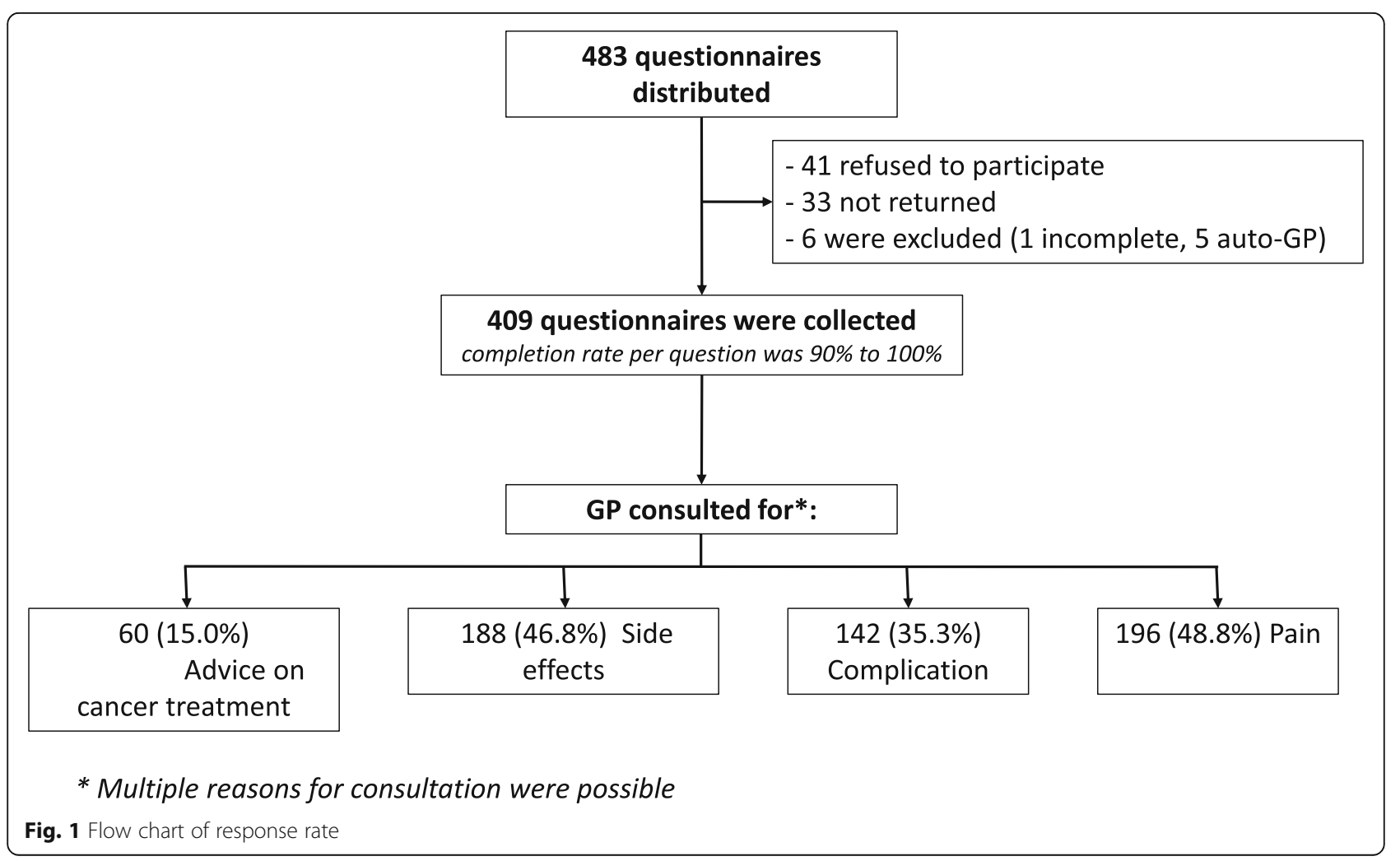


Table 1 Characteristics of patients with cancer who responded to the questionnaire $(n=403)$

\begin{tabular}{lll}
\hline \multicolumn{2}{l}{ Characteristics of the study population } & $\mathrm{n}(\%)$ \\
\hline Sex & Men & 60 \\
& Women & $(14.9 \%)$ \\
& & 343 \\
& $<50$ & $(85.1 \%)$ \\
Age (years) & 74 & $(18.4 \%)$ \\
& 50 to 75 & 287 \\
& $>75$ & $(71.2 \%)$ \\
& & 42 \\
Time since diagnosis (years) & $<1$ & $(10.4 \%)$ \\
& $\geq 1$ & 206 \\
& & $(51.2 \%)$ \\
& & 196 \\
& & $(48.8 \%)$
\end{tabular}

\section{GP/ patient relationship}

Duration of care by the same GP (years)

With change of GP since cancer diagnosis

$\begin{array}{ll}<5 & 97 \\ & (24.1 \%) \\ 5 \text { to } 15 & 109 \\ & (27.0 \%) \\ >15 & 197 \\ & (48.9 \%) \\ & 71 \\ & (17.7 \%)\end{array}$

Last visit to GP (month)

$<1$

1 to 3

4 to 6

$>6$

$\mathrm{ND}$

Participation of GP in diagnosis Yes

$N D^{*}$

\section{GP and cancer}

Last consultation was cancer-related

GP's knowledge of cancer

GP is kept informed

GP knows about last treatment
change

GP consulted for:

Advice on cancer treatment

$$
\text { Yes }
$$

Table 1 Characteristics of patients with cancer who responded to the questionnaire $(n=403)$ (Continued)

\begin{tabular}{|c|c|c|}
\hline \multicolumn{2}{|l|}{ Characteristics of the study population } & \multirow{2}{*}{$\begin{array}{l}\mathrm{n}(\%) \\
2\end{array}$} \\
\hline & $N D^{*}$ & \\
\hline \multirow[t]{2}{*}{ Side effects } & Yes & $\begin{array}{l}188 \\
(46.8 \%)\end{array}$ \\
\hline & $N D^{*}$ & 1 \\
\hline \multirow[t]{2}{*}{ Complication } & Yes & $\begin{array}{l}142 \\
(35.3 \%)\end{array}$ \\
\hline & $N D^{*}$ & 1 \\
\hline \multirow[t]{2}{*}{ Pain } & Yes & $\begin{array}{l}196 \\
(48.8 \%)\end{array}$ \\
\hline & $N D^{*}$ & 1 \\
\hline \multirow[t]{4}{*}{$\begin{array}{l}\text { Professional consulted in an } \\
\text { emergency }\end{array}$} & GP & $\begin{array}{l}173 \\
(43.8 \%)\end{array}$ \\
\hline & $\begin{array}{l}\text { Emergency } \\
\text { department }\end{array}$ & $28(7.1 \%)$ \\
\hline & $\begin{array}{l}\text { Specialized cancer } \\
\text { center }\end{array}$ & $\begin{array}{l}194 \\
(49.1 \%)\end{array}$ \\
\hline & $N D^{*}$ & 8 \\
\hline \multirow[t]{2}{*}{ GP is available in case of emergency } & Yes & $\begin{array}{l}242 \\
(62.5 \%)\end{array}$ \\
\hline & $N D^{*}$ & 16 \\
\hline \multirow[t]{2}{*}{ GP is able to manage their care } & Yes & $\begin{array}{l}225 \\
(58.3 \%)\end{array}$ \\
\hline & $N D^{*}$ & 17 \\
\hline \multicolumn{3}{|l|}{ GP/oncologist relationship } \\
\hline \multirow[t]{2}{*}{$\begin{array}{l}\text { Communication between oncologist } \\
\text { and GP }\end{array}$} & Yes & $\begin{array}{l}239 \\
(66.2 \%)\end{array}$ \\
\hline & $N D^{*}$ & 42 \\
\hline \multirow[t]{2}{*}{ GP participates in decision-making } & Yes & $\begin{array}{l}100 \\
(27.3 \%)\end{array}$ \\
\hline & $N D^{*}$ & 37 \\
\hline \multirow[t]{2}{*}{ GP's role mentioned by oncologist } & Yes & $\begin{array}{l}164(42, \\
4 \%)\end{array}$ \\
\hline & $N D^{*}$ & 16 \\
\hline
\end{tabular}

*ND: not determined

patients who consulted their GP. Thereafter, they consulted the GP more often for the management of side effects $(\mathrm{RR}=1.34, p \leq 0.01)$, pain $(\mathrm{RR}=1.55, p \leq 0.01)$, cancer-related complications $(\mathrm{RR}=1.82, p \leq 0.01)$, and for specific advice on their cancer treatment $(R R=1.83$, $p \leq 0.01$ ) (Table 3). When the patient considered that the GP and the oncologist were in communication with each other, the proportion of patients consulting for cancer treatment advice increased.

Turning to the GP in an emergency was also associated with mention of the GP's role by the oncologist $(\mathrm{RR}=1.35, p<0.01)$ (Table 3). The GP was considered to be available in an emergency by $62.5 \%(n=242)$ of patients, and competent to deliver emergency care by $58.3 \%(n=225)$. In addition, there was a very strong 
Table 2 Factors associated with a change of general practitioner

\begin{tabular}{|c|c|c|c|c|c|}
\hline & & \multicolumn{4}{|c|}{ Change of general practitioner } \\
\hline & & Yes & No & $\mathrm{RR}$ & $p$-value** \\
\hline & & $71(17.7 \%)$ & $331(82.3 \%)$ & & \\
\hline \multirow{3}{*}{$\begin{array}{l}\text { GP participation in } \\
\text { cancer diagnosis }\end{array}$} & No & $40(21.3 \%)$ & $148(78.7 \%)$ & 1 & 0.06 \\
\hline & Yes & $30(14.2 \%)$ & $181(85.8 \%)$ & 0.67 & \\
\hline & $N D^{*}$ & 1 & 2 & & \\
\hline \multirow[t]{2}{*}{ Last visit to GP (month) } & $\leq 3$ & $195(53.9 \%)$ & $167(46.1 \%)$ & 1 & 0.22 \\
\hline & $>3$ & $16(43.2 \%)$ & $21(56.8 \%)$ & 1.25 & \\
\hline
\end{tabular}

*ND: not determined ** Chi-squared test

association between confidence in the GP's availability and in their ability to deliver emergency care $(R R=3.56$, $p<0.01)$. Confidence in ability to deliver emergency care was associated with good $\mathrm{GP} /$ oncologist communication $(\mathrm{RR}=1.33, p<0.01)($ Table 3$)$.

\section{General practitioner/oncologist relationship}

The majority of patients $(n=336,85.9 \%)$ considered that the GP was kept informed by the oncologist and that the GP knew about the most recent change in their treatment (no treatment change $n=131$ ) (Table 1). Two-thirds of patients considered that the GP and the oncologist communicated with each other $(n=239$, 66.2\%), and this belief was associated with consulting the GP about cancer treatment $(\mathrm{RR}=2.14, p=0.01)$, confidence in the GP's availability $(\mathrm{RR}=1.33, p<0.01)$ and in their ability to manage the patient's care $(\mathrm{RR}=1.30, p<$ 0.01) (Table 3).

Nearly one quarter of patients $(n=100,27.3 \%)$ considered that the GP's opinion was taken into account in medical decision-making [Table 1). Those who considered that their GP was involved were more likely to turn to their GP in an emergency ( $R R=1.62, p<0.01)$, and this was also correlated with confidence in their availability $(\mathrm{RR}=1.36, p<0.01)$ and competence $(\mathrm{RR}=1.52$, $p<0.01$ ) (Table 3).

\section{Discussion}

According to the majority of patients $(n=353,88.5 \%)$, the GP was knowledgeable and capable, but few patients $(n=60,15.0 \%)$ consulted their GP for cancerrelated problems. There was a discrepancy between patients' beliefs and their behaviour. Mention by the oncologist of the GP's role increased patients' recourse to the GP. There was a correlation between patients consulting their GP in an emergency and their perception of the role attributed to the GP by the oncologist. The patient's understanding of the GP's role was determinant in the quality of the care he/she received. Good communication between the general practitioner and the oncologist improved the quality of coordination, affecting the patient's life.

\section{Strengths and limitations}

The first strength of our study is that patients' data were collected in a day hospital treating all types of cancer, which, moreover, is the regional comprehensive center that recruits patients from the whole Midi-Pyrénées region in France. The day hospital treats a large number of patients (1249 chemotherapy sessions a month, or about 60 sessions a day) who have various types of cancer and are followed by different oncologists. The size of the center allowed us through this project to study a large population of patients, with different oncology and GP practices.

The importance given to the patient's point of view allowed us to focus on patients' feelings, needs and perceptions.

A large proportion of patients were women $(n=343$, $85.1 \%)$ as there is a large proportion of women treated for breast cancer $(61.4 \%$ referred by breast specialists and $9.8 \%$ by gynaecologists) in the day unit. Worldwide, breast cancer is the cancer with the highest incidence in women, with 1.7 million new cases in 2012 (or 25\% of cancers in women) and 0.5 million deaths [2]. In addition, most treatment lines for breast cancer are administered in the day hospital, with a long survival that extends the duration of care. All in all, this leads to an over-representation of breast cancer and women in our study. So, these data are generalizable to patients suffering from breast cancer and may be reflective of the experience of patients with other cancers.

The main limitation of this study is that it analyses patient-reported data only with a high memory bias. In this paper, we wished to explore the relationships between different factors that might explain a patient's reticence to consult their GP for their cancer care. Another shortcoming is that the study does not highlight the efforts made by the main medical practitioners (oncologist and GP) but rather focuses on the effect of the medical efforts on patients' attitudes towards their GP, and the perception of the communication by the patient, which influences the patients' confidence towards his/ her various interlocutors. Another limitation of our study is a mono-centric design, which has a center effect 
Table 3 Association between patient's opinion of relationship between GP and oncologist, and reasons for GP consulting

\begin{tabular}{|c|c|c|c|c|c|c|c|}
\hline & & \multicolumn{6}{|c|}{ The patient considers that: } \\
\hline \multirow[t]{2}{*}{$\begin{array}{l}\text { The patient consults } \\
\text { their GP for: }\end{array}$} & & \multicolumn{2}{|c|}{$\begin{array}{l}\text { The oncologist } \\
\text { mentioned the } \\
\text { GP's role }\end{array}$} & \multicolumn{2}{|c|}{$\begin{array}{l}\text { The GP and the } \\
\text { oncologist } \\
\text { communicate }\end{array}$} & \multicolumn{2}{|c|}{$\begin{array}{l}\text { The GP's opinion is } \\
\text { taken into account }\end{array}$} \\
\hline & & Yes & No & Yes & No & Yes & No \\
\hline \multirow[t]{4}{*}{ Side effects } & $\begin{array}{l}\text { Yes } \\
188(46.8 \%)\end{array}$ & $\begin{array}{l}91 \\
(55.5 \%)\end{array}$ & $\begin{array}{l}92 \\
(41.4 \%)\end{array}$ & $\begin{array}{l}121 \\
(50.6 \%)\end{array}$ & $\begin{array}{l}56 \\
(46.3 \%)\end{array}$ & $48(48.0 \%)$ & $\begin{array}{l}124 \\
(46.8 \%)\end{array}$ \\
\hline & $\begin{array}{l}\text { No } \\
214(53.2 \%)\end{array}$ & $73(44.5 \%)$ & $\begin{array}{l}130 \\
(58.6 \%)\end{array}$ & $\begin{array}{l}118 \\
(49.4 \%)\end{array}$ & $\begin{array}{l}65 \\
(53.7 \%)\end{array}$ & $52(52.0 \%)$ & $\begin{array}{l}141 \\
(53.2 \%)\end{array}$ \\
\hline & $\mathbf{R R}$ & 1.34 & 1 & 1.09 & 1 & 1.03 & 1 \\
\hline & $p$-value* & $<0.01$ & & 0.44 & & 0.84 & \\
\hline \multirow[t]{4}{*}{ Pain } & $\begin{array}{l}\text { Yes } \\
196(48.8 \%)\end{array}$ & $101(61.6 \%)$ & $\begin{array}{l}88 \\
(39.6 \%)\end{array}$ & $\begin{array}{l}119 \\
(49.8 \%)\end{array}$ & $\begin{array}{l}60 \\
(49.6 \%)\end{array}$ & $57(57.0 \%)$ & $\begin{array}{l}126 \\
(47.5 \%)\end{array}$ \\
\hline & $\begin{array}{l}\text { No } \\
206(51.2 \%)\end{array}$ & $\begin{array}{l}63 \\
(38.4 \%)\end{array}$ & $\begin{array}{l}134 \\
(60.4 \%)\end{array}$ & $120(50.2 \%)$ & $\begin{array}{l}61 \\
(50.4 \%)\end{array}$ & $43(43.0 \%)$ & $\begin{array}{l}139 \\
(52.5 \%)\end{array}$ \\
\hline & $\mathbf{R R}$ & 1.55 & 1 & 1.00 & 1 & 1.20 & 1 \\
\hline & $p$-value* & $<0.01$ & & 0.97 & & 0.11 & \\
\hline \multirow[t]{4}{*}{$\begin{array}{l}\text { Cancer-related } \\
\text { complications }\end{array}$} & $\begin{array}{l}\text { Yes } \\
142(35.3)\end{array}$ & $\begin{array}{l}78 \\
(47.6 \%)\end{array}$ & $\begin{array}{l}58 \\
(26.1 \%)\end{array}$ & $\begin{array}{l}92 \\
(38.5 \%)\end{array}$ & $\begin{array}{l}41 \\
(33.9 \%)\end{array}$ & $\begin{array}{l}47 \\
(47.0 \%)\end{array}$ & $\begin{array}{l}81 \\
(30.6 \%)\end{array}$ \\
\hline & $\begin{array}{l}\text { No } \\
260(64.7)\end{array}$ & $\begin{array}{l}86 \\
(52.4 \%)\end{array}$ & $\begin{array}{l}164 \\
(73.9 \%)\end{array}$ & $\begin{array}{l}147 \\
(61.5 \%)\end{array}$ & $\begin{array}{l}80 \\
(66.1 \%)\end{array}$ & $\begin{array}{l}53 \\
(53.0 \%)\end{array}$ & $\begin{array}{l}184 \\
(69.4 \%)\end{array}$ \\
\hline & RR & 1.82 & 1 & 1.14 & 1 & 1.54 & 1 \\
\hline & $p-$ value $^{*}$ & $<0.01$ & & 0.39 & & $<0.01$ & \\
\hline \multirow[t]{4}{*}{$\begin{array}{l}\text { Advice on cancer } \\
\text { treatment }\end{array}$} & $\begin{array}{l}\text { Yes } \\
60(15.0)\end{array}$ & $\begin{array}{l}34 \\
(20.7 \%)\end{array}$ & $\begin{array}{l}25 \\
(11.3 \%)\end{array}$ & $\begin{array}{l}47 \\
(19.7 \%)\end{array}$ & $\begin{array}{l}11 \\
(9.2 \%)\end{array}$ & $\begin{array}{l}29 \\
(29.0 \%)\end{array}$ & $\begin{array}{l}26 \\
(9.8 \%)\end{array}$ \\
\hline & $\begin{array}{l}\text { No } \\
341(85.0)\end{array}$ & $\begin{array}{l}130 \\
(79.3 \%)\end{array}$ & $\begin{array}{l}196 \\
(88.7 \%)\end{array}$ & $\begin{array}{l}192 \\
(80.3 \%)\end{array}$ & $\begin{array}{l}109 \\
(90.8 \%)\end{array}$ & $\begin{array}{l}71 \\
(71.0 \%)\end{array}$ & $\begin{array}{l}238 \\
(90.2 \%)\end{array}$ \\
\hline & $\mathbf{R R}$ & 1.83 & 1 & 2.14 & 1 & 2.94 & 1 \\
\hline & $p$-value* & 0.01 & & 0.01 & & $<0.01$ & \\
\hline \multirow[t]{4}{*}{ Emergency } & $\begin{array}{l}\text { Yes } \\
173(43.8)\end{array}$ & $\begin{array}{l}82 \\
(51.25 \%)\end{array}$ & $\begin{array}{l}83 \\
(37.9 \%)\end{array}$ & $\begin{array}{l}111 \\
(47.2 \%)\end{array}$ & $\begin{array}{l}51 \\
(42.9 \%)\end{array}$ & $\begin{array}{l}60 \\
(61.2 \%)\end{array}$ & $\begin{array}{l}98 \\
(37.7 \%)\end{array}$ \\
\hline & $\begin{array}{l}\text { No } \\
222(56.2)\end{array}$ & $\begin{array}{l}78 \\
(48.75 \%)\end{array}$ & $\begin{array}{l}136 \\
(62.1 \%)\end{array}$ & $\begin{array}{l}124 \\
(52.8 \%)\end{array}$ & $\begin{array}{l}68 \\
(57.1 \%)\end{array}$ & $\begin{array}{l}38 \\
(38.8 \%)\end{array}$ & $\begin{array}{l}162 \\
(62.3 \%)\end{array}$ \\
\hline & $\mathbf{R R}$ & 1.35 & 1 & 1.10 & 1 & 1.62 & 1 \\
\hline & $p$-value* & $<0.01$ & & 0.43 & & $<0.01$ & \\
\hline \multicolumn{8}{|l|}{$\begin{array}{l}\text { The patient } \\
\text { considers } \\
\text { that the GP is: }\end{array}$} \\
\hline \multirow[t]{4}{*}{$\begin{array}{l}\text { Able to manage } \\
\text { their care }\end{array}$} & $\begin{array}{l}\text { Yes } \\
225 \text { (58.3\%) }\end{array}$ & $\begin{array}{l}99 \\
(64.3 \%)\end{array}$ & $\begin{array}{l}118 \\
(54.1 \%)\end{array}$ & $\begin{array}{l}148 \\
(64.3 \%)\end{array}$ & $\begin{array}{l}59 \\
(49.6 \%)\end{array}$ & $\begin{array}{l}73 \\
(77.7 \%)\end{array}$ & $\begin{array}{l}132 \\
(51.2 \%)\end{array}$ \\
\hline & $\begin{array}{l}\text { No } \\
161 \text { (41.7\%) }\end{array}$ & $\begin{array}{l}55 \\
(35.7 \%)\end{array}$ & $\begin{array}{l}100 \\
(45.9 \%)\end{array}$ & $\begin{array}{l}82 \\
(35.7 \%)\end{array}$ & $\begin{array}{l}60 \\
(50.4 \%)\end{array}$ & $\begin{array}{l}21 \\
(22.3 \%)\end{array}$ & $\begin{array}{l}126 \\
(48.8 \%)\end{array}$ \\
\hline & RR & 1.19 & 1 & 1.30 & 1 & 1.52 & 1 \\
\hline & $P$ value* & 0.05 & & $<0.01$ & & $<0.01$ & \\
\hline \multirow[t]{4}{*}{$\begin{array}{l}\text { Available in case } \\
\text { of emergency }\end{array}$} & $\begin{array}{l}\text { Yes } \\
242(62.5 \%)\end{array}$ & $\begin{array}{l}105 \\
(67.7 \%)\end{array}$ & $\begin{array}{l}130 \\
(59.9 \%)\end{array}$ & $\begin{array}{l}162 \\
(69.8 \%)\end{array}$ & $\begin{array}{l}62 \\
(52.5 \%)\end{array}$ & $\begin{array}{l}74 \\
(77.9 \%)\end{array}$ & $\begin{array}{l}147 \\
(57.2 \%)\end{array}$ \\
\hline & $\begin{array}{l}\text { No } \\
145 \text { (37.5\%) }\end{array}$ & $\begin{array}{l}50 \\
(32.2 \%)\end{array}$ & $\begin{array}{l}87 \\
(40.1 \%)\end{array}$ & $\begin{array}{l}70 \\
(30.2 \%)\end{array}$ & $\begin{array}{l}56 \\
(47.5 \%)\end{array}$ & $\begin{array}{l}21 \\
(22.1 \%)\end{array}$ & $\begin{array}{l}110 \\
(42.8 \%)\end{array}$ \\
\hline & RR & 1.13 & 1 & 1.33 & 1 & 1.36 & 1 \\
\hline & $p$-value* & 0.12 & & $<0.01$ & & $<0.01$ & \\
\hline
\end{tabular}


and a selection bias. We chose a quantitative instead of a qualitative method to measure the lack of communication between oncologist and GP, and compared our results with the literature.

We wished to look for association between different factors that could explain patients' reticence to consult their GP for their cancer care. We sought to have a large sample of patients with cancers in our study in order to be as representative as possible of our study population despite our mono-centric study. In addition, closedended questions allowed us to assess the presence of associations between patients' responses. These elements justify our choice of a quantitative rather than a qualitative method.

\section{Comparison with existing literature}

Shared decision-making needs to take place with the patient (patient-centered), because it is an important step in the patient's life that impacts their perception of the disease [25]. The patient's frequency of consultation with the GP prior to diagnosis can impact the stage of cancer diagnosis and therefore early diagnosis of cancer [26], especially since there is a strong association between GP-estimated cancer risk at referral and probability of cancer [27]. The GP, using a holistic approach, should be an attentive partner to share adequate decision-making in complex cancer treatments with the patient, in collaboration with other specialists [28]. Several qualitative studies have been published on patients' perceptions of their cancer management [29], their relationship with the healthcare team [30] and their interest in medical education [31, 32]. Other studies have examined the perceptions of healthcare teams on their patients' treatment [33-35]. These studies revealed a number of factors leading to communication difficulties between the patient, the oncologist and the GP. These difficulties can include a lack of direct communication between oncologists or GPs, the lack of two-way communication tools between professionals, the need to set up a patient centred management system and to allow a prolonged follow-up of patients by the GP. Furthermore the quality of the relationship between physician and patient could be a survival factor [36]. In our study, we found that increasing communication between different practitioners, in a way that is perceptible to the patient, reduces the use of emergency departments and increases the use of GPs in primary care. This makes it clear that by improving communication and coordination between GPs and oncologists, we have a direct impact on quality of life (less hospitalization, patient-friendly management) and on the patient's survival [30-36].

Participation of the GP in diagnosis of cancer was estimated at $52.8 \%$ by patients. Three-quarters of patients had been followed by the same GP for more than 5 years, and half had been diagnosed within the previous year. There is a strong perception by the patient of the involvement of the GP in the diagnosis, as the GP follows the patient over the long term. The literature indicates that the investigations necessary for diagnosis are mainly prescribed by the GP [37]. The patient is then referred to the oncologist by the GP (passing from primary to hospital care) and once the pathology results are available the oncologist discloses the diagnosis of cancer. In France, the National Cancer Plan provides for a diagnosis disclosure procedure which consists of four consecutive phases: a medical phase (discussion between oncologist and patient), a phase of consultation on nursing and care provision needs, and a phase dealing with access to supportive care, while the last phase deals with communication with the GP [9]. During this last phase, the GP is informed about the diagnosis, the cancer treatment program, its side effects and the planned hospital consultations. In practice, this stage is often neglected; the literature finds that the GP is delegated to disclose the diagnosis to the patient in 19\% of cases and that it is the patient who discloses their own diagnosis to the GP in $18 \%$ of cases [9]. Involving the GP in all the stages leading up to treatment optimizes follow-up and care coordination [38, 39]. Furthermore, the implication of the general practitioner in the health care decreases the number of visits to the emergency department $[39,40]$. Our findings suggest that oncologists should inform the patient about the role of their GP. It thus seems indispensable for oncology departments to develop guidelines [41] to optimize patient-centered management, adapted to outpatient medicine. If the oncology department proposed that the patient should have a consultation with their GP following the diagnosis disclosure consultation, the GP would regain their role. The patient would then be in formal contact with their GP for management of their cancer, and a link would be created between the hospital and primary care. Jiwa et al. showed that this professional network between GP and other specialists impacts early diagnosis [42].

Our work underlines the need for communication between all those involved [20,43], as well as the fact that this communication must be visible and made explicit to the patient. It probably increases confidence because we showed that when the patient believes that there is good communication between the GP and the oncologist, the number of patients consulting specifically for a cancer-related problem increases, whether in an emergency or not. The literature shows that GPs believe that there is room for improvement in their communication with oncologists [23, 44]. Although deeply involved in the management of patients with cancer, GPs feel isolated at crucial moments of the illness, and when making decisions at these times [33]. Many studies [12, 13, $17,20,44$ ] reported unsatisfactory communication between 
GPs and oncologists. According to these authors, gaps exist in the transmission of information on patients to GPs. GPs felt that their specialist colleagues regarded them almost with contempt and, finally, that the specialists 'captured' certain of their patients. A qualitative study showed that GPs are more involved in the management of their patients with cancers because they have better access to communication with oncologists [45]. Another study [46] confirmed their desire to be involved in patient management and their regret regarding the poor communication with their oncologist colleagues [47]. Finally, patients themselves call for better cooperation between the physicians involved in their care [48]. Good communication between the different physicians is indispensable for good holistic patient care, particularly in complex situations [23, 24] or at the end of life [11]. Coordinating care for the patient suffering from cancer is affected by the relationship between the GP and the patient $[23,49]$.

\section{Implications}

Systematically integrating a GP consultation in the cancer course of a patient could improve management and care coordination. Ideally, this involvement should be from the beginning, or after the announcement. This concept must be tested and evaluated in real practice, as a prospective study.

It could also be interesting to conduct co-training with oncologists and GPs. This would make it possible to develop a common care pathway between practitioners, for which communication would be planned and organised, allowing better coordination of care. Practitioners could use a common basis of advice and recommendation for supportive care and follow-up. The tools thus created could be used on electronic support for patient-centered coordination.

\section{Conclusion}

The way in which patients perceive the relationship between their GP and their oncologist affects their healthcare utilization during their cancer care. The way in which the oncologist presents the GP's role conditions patient management, and determines whether it will be possible in a primary care setting or not. This presentation is one of the keys of coordination between primary care and the hospital.

The general practitioner is an important contact and source of support for the patient. The GP must form an integral part of the medical team that will follow the patient throughout the management of the disease. Communication between the different physicians caring for the patient, together with communication between these physicians and the patient, is crucial for optimal management where each can fully play their own role. Further studies should demonstrate the impact of communication between the hospital and general practice in the management of patients suffering from cancer.

\section{Supplementary information}

Supplementary information accompanies this paper at https://doi.org/10. 1186/s12885-020-06993-0.

Additional file 1. Patients' perspective on the role of their general practitioner in cancer management - French version. Questionnaire.

Additional file 2. Patients' perspective on the role of their general practitioner in cancer management - English version. Questionnaire.

\section{Abbreviations}

GP: General Practitioner; RR: Risk Ratio

\section{Acknowledgements}

The authors wish to thank Thierry Paricaud for his availability, all the team of Day Hospital 2B for their involvement which made it possible to develop the questionnaire, and Oncology Department $1 \mathrm{~A}$ for their assistance in its conception especially to Virginie Fabre and Kanoun Dorra.

\section{Authors' contributions}

$V D, N B$ conceptualized and carried out the research preliminary to the work. $V D, L G$ and KP designed the questionnaire. MERB validated the questionnaire. VD and KP carried out the data collection. VD, JPD and PG analysed and interpreted the data. VD and MERB were the major contributor in writing the manuscript. All authors read and approved the final manuscript.

\section{Funding}

No funding was received.

\section{Availability of data and materials}

The datasets used and analysed during the current study are available from the corresponding author on reasonable request.

\section{Ethics approval and consent to participate}

This study was approved by the ethical committee of the university department of Toulouse N²015-061 of 22nd June 2015, and was conform to the 1964 Helsinki declaration and its later amendments or comparable ethical standards.

Verbal inform consent was obtained from all participants. The ethics committee, in accordance with French law, did not request written consent. Verbal consent alone was requested because the participation of patients in this study did not affected their medical care.

Consent for publication

Not applicable.

Competing interests

The authors declare that they have no competing interests.

\section{Author details}

${ }^{1}$ Department of Primary Care, University of Toulouse, 133 Route de Narbonne, 31062 Toulouse, France. ${ }^{2}$ Oncology Unit, Auch Hospital, Auch, France. ${ }^{3}$ Paul Sabatier University, Toulouse III, 133 Route de Narbonne, 31062 Toulouse, France. ${ }^{4}$ Inserm U1027, Faculty of Medicine, 37 allées Jules Guesde, 31073 Toulouse, France. ${ }^{5}$ Department of Internal Medicine, Toulouse University Hospital, 29 Rue Emile Lecrivain, 31077 Toulouse, France. ${ }^{6}$ Institut Universitaire du Cancer de Toulouse-Oncopole, 1 Av. Irène Joliot-Curie, 31100 Toulouse, France. ${ }^{7}$ Onco-occitanie, 1 Av. Irène Joliot-Curie, 31059 Toulouse, France.

Received: 30 December 2019 Accepted: 22 May 2020

Published online: 01 June 2020

\section{References}

1. Stewart BW, Wild CP. World Cancer report 2014. Lyon: International Agency for Research on Cancer/World Health Organization; 2014.

2. Ferlay J, Soerjomataram I, Dikshit R, Eser S, Mathers C, Rebelo M, et al. Cancer incidence and mortality worldwide: sources, methods and major patterns in GLOBOCAN 2012. Int J Cancer. 2015;136(5):E359-86. 
3. Belot A, Grosclaude P, Bossard N, Jougla E, Benhamou E, Delafosse P, et al Cancer incidence and mortality in France over the period 1980-2005. Rev Epidemiol Sante Publique. 2008;56(3):159-75.

4. Binder-Foucard F, Belot A, Delafosse P, Remontet L, Woronoff AS, Bossard N Estimation nationale de l'incidence et de la mortalité par cancer en France entre 1980 et 2012: étude à partir des registres des cancers du réseau Francim [Internet]. Saint-Maurice: Institut de veille sanitaire; 2013. Available from: http://opac.invs.sante.fr/index.php?lvl=notice_display\&id=11619.

5. Tardieu É, Thiry-Bour C, Devaux C, Ciocan D, de Carvalho V, Grand M, et al. The place of general practitioners in cancer care in Champagne-Ardenne. Bull Cancer (Paris). 2012;99(5):557-62.

6. Summerton N. General practitioners and cancer. BMJ. 2000;320(7242):1090-1.

7. Hamilton W. Cancer diagnosis in primary care. Br J Gen Pract. 2010; 60(571):121-8.

8. Klabunde CN, Han PKJ, Earle CC, Smith T, Ayanian JZ, Lee R, et al. Physician roles in the cancer-related follow-up care of cancer survivors. Fam Med. 2013;45(7):463-74

9. Rougé Bugat M-E, Omnes C, Delpierre C, Escourrou E, Boussier N, Oustric S, et al. Primary care physicians and oncologists are partners in cancer announcement. Support Care Cancer. 2016;24(6):2473-9.

10. Vernant J-P, Grünfeld J-P. 3rd cancer plan. Rev Prat. 2013;63(9):1197-8.

11. Oosterink JJ, Oosterveld-Vlug MG, Glaudemans JJ, Pasman HRW, Willems DL, Onwuteaka-Philipsen BD. Interprofessional communication between oncologic specialists and general practitioners on end-of-life issues needs improvement. Fam Pract. 2016;33(6):727-32.

12. Renovanz M, Keric N, Richter C, Gutenberg A, Giese A. Patient-centered care. Improvement of communication between university medical centers and general practitioners for patients in neuro-oncology. Nervenarzt. 2015; 86(12):1555-60.

13. Gonzalo JD, Himes J, McGillen B, Shifflet V, Lehman E. Interprofessional collaborative care characteristics and the occurrence of bedside interprofessional rounds: a cross-sectional analysis. BMC Health Serv Res. 2016;16:459.

14. Grunfeld E, Earle CC. The interface between primary and oncology specialty care: treatment through survivorship. J Natl Cancer Inst Monogr. 2010;2010(40):25-30.

15. Balla Jl, Jamieson WE. Improving the continuity of care between general practitioners and public hospitals. Med J Aust. 1994;161(11-12):656-9.

16. Tandjung R, Rosemann T, Badertscher N. Gaps in continuity of care at the interface between primary care and specialized care: general practitioners' experiences and expectations. Int J Gen Med. 2011;4:773-8.

17. Anvik T, Holtedahl KA, Mikalsen $H$. 'When patients have cancer, they stop seeing $\mathrm{me}^{\prime}$--the role of the general practitioner in early follow-up of patients with cancer--a qualitative study. BMC Fam Pract. 2006;7:19.

18. Davis K, Schoenbaum SC, Audet A-M. A 2020 vision of patient-centered primary care. J Gen Intern Med. 2005;20(10):953-7.

19. Flieger SP. Implementing the patient-centered medical home in complex adaptive systems: becoming a relationship-centered patient-centered medical home. Health Care Manag Rev. 2016;2:112.

20. Dworkind M, Towers A, Murnaghan D, Guibert R, Iverson D. Communication between family physicians and oncologists: qualitative results of an exploratory study. Cancer Prev Control. 1999;3(2):137-44.

21. Lang V, Walter S, Fessler J, Koester MJ, Ruetters D, Huebner J. The role of the general practitioner in cancer care: a survey of the patients' perspective. J Cancer Res Clin Oncol. 2017;143(5):895-904.

22. Nugteren IC, Duineveld LAM, Wieldraaijer T, van Weert HCPM, Verdonck-de Leeuw IM, van Uden-Kraan CF, et al. Need for general practitioner involvement and eHealth in colon cancer survivorship care: patients perspectives. Fam Pract. 2017;34(4):473-8.

23. Meiklejohn JA, Mimery A, Martin JH, Bailie R, Garvey G, Walpole ET, et al. The role of the GP in follow-up cancer care: a systematic literature review. J Cancer Surviv Res Pract. 2016;10(6):990-1011.

24. Halkett GKB, Jiwa M, Lobb EA. Patients' perspectives on the role of their general practitioner after receiving an advanced cancer diagnosis. Eur J Cancer Care (Engl). 2015;24(5):662-72.

25. Gulbrandsen P, Clayman ML, Beach MC, Han PK, Boss EF, Ofstad EH, et al. Shared decision-making as an existential journey: aiming for restored autonomous capacity. Patient Educ Couns. 2016;99(9):1505-10.

26. Jensen $H$, Vedsted $P$, Møller $H$. Prognosis of cancer in persons with infrequent consultations in general practice: A population-based cohort study. Int J Cancer. 2017;141(12):2400-9.

27. Ingeman ML, Christensen MB, Bro F, Knudsen ST, Vedsted P. The Danish cancer pathway for patients with serious non-specific symptoms and signs of cancer-a cross-sectional study of patient characteristics and cancer probability. BMC Cancer. 2015;15:421.

28. de Wit NJ. A 'time out consultation' in primary care for elderly patients with cancer: Better treatment decisions by structural involvement of the general practitioner. Eur J Cancer Care (Engl). 2017;26:3.

29. Thomsen TG, Hølge-Hazelton B. Patients' vulnerability in follow-up after colorectal Cancer: a qualitative action research study. Cancer Nurs. 2016;1:152.

30. Santoso JT, Yibirin E, Crigger M, Wan J, ElNaggar AC. Incidence and contributing factors to termination of the patient-physician relationship. Gynecol Oncol Rep. 2016;17:42-4.

31. Stewart M, Brown JB, Hammerton J, Donner A, Gavin A, Holliday RL, et al. Improving communication between doctors and breast cancer patients. Ann Fam Med. 2007;5(5):387-94.

32. Easley J, Miedema B, O'Brien MA, Carroll J, Manca D, Webster F, et al. The role of family physicians in cancer care: perspectives of primary and specialty care providers. Curr Oncol Tor Ont. 2017;24(2):75-80.

33. Chicoulaa B, Balardy L, Stillmunkes A, Mourey L, Oustric S, Rouge Bugat M-E. French general practitioners' sense of isolation in the management of elderly cancer patients. Fam Pract. 2016;33(5):551-6.

34. Smidt K, Mackenzie L, Dhillon H, Vardy J, Lewis J, Loh SY. The perceptions of Australian oncologists about cognitive changes in cancer survivors. Support Care Cancer. 2016;24(11):4679-87.

35. Duineveld LAM, Wieldraaijer T, Wind J, Verdonck-de Leeuw IM, van Weert HCPM, van Uden-Kraan CF. Primary care-led survivorship care for patients with colon cancer and the use of eHealth: a qualitative study on perspectives of general practitioners. BMJ Open. 2016;6(4):e010777.

36. Frenkel M, Engebretson JC, Gross S, Peterson NE, Giveon AP, Sapire K, et al. Exceptional patients and communication in cancer care-are we missing another survival factor? Support Care Cancer. 2016;24(10):4249-55.

37. Summerton N. Diagnosis and general practice. Br J Gen Pract. 2000;50(461): 995-1000.

38. Brandenbarg D, Roorda C, Stadlander M, de Bock GH, Berger MY, Berendsen AJ. Patients' views on general practitioners' role during treatment and follow-up of colorectal cancer: a qualitative study. Fam Pract. 2016;5.

39. Duflos C, Antoun S, Loirat P, DiPalma M, Minvielle E. Identification of appropriate and potentially avoidable emergency department referrals in a tertiary cancer care center. Support Care Cancer. 2017;25(8):2377-85.

40. Toftegaard BS, Bro F, Falborg AZ, Vedsted P. Impact of a continuing medical education meeting on the use and timing of urgent cancer referrals among general practitioners - a before-after study. BMC Fam Pract. 2017;18(1):44.

41. Dillmon M, Goldberg JM, Ramalingam SS, Mayer RJ, Loehrer P, Van Poznak C. Clinical practice guidelines for Cancer care: utilization and expectations of the practicing oncologist. J Oncol Pract. 2012;8(6):350-3.

42. Jiwa $M$, Halkett $G$, Aoun $S$, Arnet $H$, Smith M, Pilkington $M$, et al. Factors influencing the speed of cancer diagnosis in rural Western Australia: a general practice perspective. BMC Fam Pract. 2007:8:27.

43. Dossett LA, Hudson JN, Morris AM, Lee MC, Roetzheim RG, Fetters MD, et al. The primary care provider (PCP)-cancer specialist relationship: a systematic review and mixed-methods meta-synthesis. CA Cancer J Clin. 2017;67(2):156-69.

44. Rougé Bugat ME, Dufossé V, Paul C, Oustric S, Meyer N. Communicating information to the general practitioner: the example of vemurafenib for metastatic melanoma. J Eur Acad Dermatol Venereol. 2015;11.

45. Johansen M-L, Holtedahl KA, Rudebeck CE. A doctor close at hand: how GPS view their role in cancer care. Scand J Prim Health Care. 2010;28(4):249-55.

46. Fidjeland HL, Brekke M, Vistad I. General practitioners' attitudes toward follow-up after cancer treatment: a cross-sectional questionnaire study. Scand J Prim Health Care. 2015;33(4):223-32.

47. Dahlhaus A, Vanneman N, Guethlin C, Behrend J, Siebenhofer A. German general practitioners' views on their involvement and role in cancer care: a qualitative study. Fam Pract. 2014;31(2):209-14.

48. Lundstrøm LH, Johnsen AT, Ross L, Petersen MA, Groenvold M. Crosssectorial cooperation and supportive care in general practice: cancer patients' experiences. Fam Pract. 2011;28(5):532-40.

49. Franco BB, Dharmakulaseelan L, McAndrew A, Bae S, Cheung MC, Singh S. The experiences of cancer survivors while transitioning from tertiary to primary care. Curr Oncol Tor Ont. 2016;23(6):378-85.

\section{Publisher's Note}

Springer Nature remains neutral with regard to jurisdictional claims in published maps and institutional affiliations. 